\title{
Endothelium-derived Relaxing Factor Inhibits Transport and Increases cGMP Content in Cultured Mouse Cortical Collecting Duct Cells
}

\author{
Barbara A. Stoos, Oscar A. Carretero, Rodolfo D. Farhy, Gloria Scicli, and Jeffrey L. Garvin \\ Hypertension and Vascular Research Division, Department of Medicine, and Heart and Vascular Institute, \\ Henry Ford Hospital, Detroit, Michigan 48202
}

\begin{abstract}
Stimulation of the release of endothelium-derived relaxing factor (EDRF) in the kidney has been shown to result in natriuresis without affecting glomerular filtration rate. This may be due to EDRF directly regulating solute transport in the cortical collecting duct (CCD). To test this hypothesis, we measured the effect of bradykinin (Bk) or acetylcholine (Ach) on short-circuit current $\left(I_{s c} ;\right.$ a measure of active transport) in a $C C D$ cell line (M-1), in the presence or absence of cow pulmonary artery endothelial (CPAE) cells. $10^{-9} \mathrm{M}$ Bk or $10^{-7} \mathrm{M}$ Ach had no effect on $M-1 I_{s c}$ in which CPAE cells were absent. The addition of CPAE cells to $M-1$ cells also did not affect $M-1 I_{s c}$. On the other hand, when $10^{-9} \mathrm{M} B \mathrm{Bk}$ or $10^{-7} \mathrm{M}$ Ach were added to M-1 cells in the presence of CPAE cells, $I_{s c}$ decreased from $43 \pm 4.5$ to $26 \pm 4$ and $64 \pm 9$ to $33 \pm 4 \mu \mathrm{A} / \mathrm{cm}^{2}$, respectively $(P$ $<0.001$ ). Nitroarginine ( $\mathrm{N}$-Arg, $10^{-4} \mathrm{M}$ ), a competitive inhibitor of EDRF production, blocked the inhibition in $M-1 I_{s c}$ due to both agonists. Since cGMP is the second messenger of EDRF in vascular smooth muscle, we measured the effects of Bk on cGMP production in M-1 cells in the presence and absence of CPAE cells. Bk increased cGMP content in M-1 cells in the presence of CPAE cells from $33 \pm 3.4$ to $132 \pm 11.7 \mathrm{fmol} /$ $10^{6} \mathrm{M}-1$ cells $(P<0.001)$. When cultures of M-1 and CPAE cells were treated with $\mathrm{N}$-Arg and challenged with $\mathrm{Bk}$, Bk's effect on cGMP was partially blocked $\left(61.4 \pm 12 \mathrm{fmol} / 10^{-6} \mathrm{M}-1\right.$ cells; NS). These data suggest that EDRF inhibits transport and increases cGMP content in M-1 cells. (J. Clin. Invest. 1992. 89:761-765.) Key words: endothelial cells • short-circuit current $\bullet$ potential difference
\end{abstract}

\section{Introduction}

Endothelium-dependent relaxation of blood vessels results from the release of a diffusible substance with a plasma half-life of $<30 \mathrm{~s}$, termed endothelium-derived relaxing factor (EDRF). ${ }^{1}$ Experimental evidence suggests that EDRF may be

Address reprint requests to J. L. Garvin, M. D., Henry Ford Hospital, Hypertension and Vascular Research Division, Detroit, MI 48202.

Received for publication 16 May 1991 and in revised form 4 September 1991 .

1. Abbreviations used in this paper: Ach, acetylcholine; BK, bradykinin; CCD, cortical collecting duct; CPAE, cow pulmonary artery endothelial; EDRF, edothelium-derived relaxing factor; $I_{s c}$, short-circuit current; M-1, a CCD cell line; N-Arg, nitroarginine; PD, transepithelial potential difference.

J. Clin. Invest.

(C) The American Society for Clinical Investigation, Inc.

0021-9738/92/03/0761/05 \$2.00

Volume 89, March 1992, 761-765 either NO (1) or a nitrosothiol such as s-nitrosocysteine $(2,3)$. The synthesis of EDRF is thought to be from the amino acid L-arginine (4); and its release can be stimulated by a variety of agents, including bradykinin (Bk) and acetylcholine (Ach) (1, 5). $\mathrm{L}-\mathrm{N}^{\mathrm{G}}$-nitroarginine (N-Arg), a guanidino-substituted L-arginine analogue, is a competitive inhibitor of EDRF synthesis (6). The mechanism of action of EDRF in vasorelaxation involves activation of soluble guanylate cyclase, which causes intracellular cGMP to increase $(7,8)$. Inhibition of soluble guanylate cyclase by methylene blue blocks EDRF-induced relaxation (9).

Intrarenal infusion of $\mathrm{Bk}$ or Ach, resulting in release of EDRF, has been shown to cause diuresis and natriuresis without affecting glomerular filtration rate $(10,11)$. This may be due to EDRF mediation of hemodynamic changes, a direct inhibition of tubular transport, or both. Although no direct action of EDRF inhibiting transport in individual nephron segments has been reported to date, it is an intriguing possibility since cGMP, which has been shown to act as EDRF's second messenger $(7,8)$, also inhibits transport in the collecting duct. Atrial natriuretic factor, which acts by increasing intracellular cGMP content (12), inhibits both sodium and water transport in the cortical and inner medullary collecting duct (13-15). Additionally, Zeidel and colleagues (14) have shown that sodium nitroprusside, an activator of soluble guanylate cyclase, inhibits sodium entry into inner medullary collecting duct cells. Therefore, EDRF may be capable of regulating transport in these segments by a mechanism involving cGMP.

To test these possibilities, we measured the effect of Bk or Ach on short-circuit current $\left(\mathrm{I}_{\mathrm{sc}}\right)$, a measure of active transport, in a cortical collecting duct (CCD) cell line $\mathrm{M}-1$, in the presence or absence of cow pulmonary artery endothelial (CPAE; CCL 209; American Type Culture Collection, Rockville, MD) cells. To determine whether an effect on $I_{s c}$ was due to EDRF release by CPAE cells, we also measured the effect of Bk and Ach on M-1 $I_{s c}$ in the presence of CPAE cells treated with N-Arg or methylene blue. Since cGMP can inhibit transport in the CCD, we measured the effects of $\mathrm{Bk}$ on cGMP production in $\mathrm{M}-1$ cells in the presence and absence of CPAE cells, with and without N-Arg.

These experiments were performed with cultured cells because transport is easily measured, there are abundant cells for cGMP measurements, and hemodynamic effects of EDRF can be avoided. These studies suggest that EDRF decreases transport and elevates cGMP levels in cultured CCD cells.

\section{Methods}

Cell line. The M-1 cell line was originally developed from a mouse transgenic for the early region of simian virus $40, \mathrm{Tg}(\mathrm{SV} 40 \mathrm{E}) \mathrm{Bri} / 7$, and has been reported to retain many of the transport functions and hormone responsiveness of the CCD (16). M-1 cells were grown on perme- 
able collagen membranes (Cellegen units; ICN Biochemicals, Cleveland, $\mathrm{OH}$ ) and maintained on PC-1 medium (Ventrex Laboratories, Portland, ME) supplemented with 5\% fetal bovine serum and antibiotics. Monolayers from passages 7-13 were randomly selected and used in the following studies. M-1 cells demonstrate no significant difference in transport characteristics during these passages (16).

CPAE cell line. CPAE cells were grown on cross-linked collagen microcarriers (Ventrex Laboratories) and maintained on Dulbecco's modified essential medium supplemented with $20 \%$ fetal bovine serum. Confluent microcarriers were added to $M-1$ monolayers in a cell ratio of $\sim 1: 1$ for transport studies and cGMP measurements.

Bioassay of EDRF production by CPAE cells. Left circumflex coronary arteries were removed from anesthetized mongrel dogs. Excised tissues were placed in cold Krebs-Ringer salt solution (mM: 118.3 $\mathrm{NaCl}, 4.7 \mathrm{KCl}, 2.5 \mathrm{CaCl}_{2}, 1.2 \mathrm{MgSO}_{4}, 1.2 \mathrm{KH}_{2} \mathrm{PO}_{4}, 25.0 \mathrm{NaHCO}_{3}$, $0.026 \mathrm{Ca}-\mathrm{EDTA}$, and 11.1 glucose), cleaned of connective tissue, and cut into rings ( $5-\mathrm{mm}$ length). The endothelium was removed by gently rolling the luminal surface with small forceps. The ring was mounted between two stirrups, one anchored to a steel plate, the other connected to a strain gauge transducer (model FT03C; Grass Instrument Co., Quincy, MA) for the recording of isometric force. The bioassay ring could move freely below two vertically mounted polypropylene chromatographic columns (i.d. $7 \mathrm{~mm}$ ) maintained at $37^{\circ} \mathrm{C}$ by a water jacket. One column was filled with CPAE cells on microcarrier beads (endothelial superfusion) and the other with microcarrier beads without CPAE cells (direct superfusion). Each column was perfused at a constant flow ( $3 \mathrm{ml} / \mathrm{min}$ ) by means of a roller pump, with the salt solution oxygenated with a $95 \% \mathrm{O}_{2}$ and $5 \% \mathrm{CO}_{2}$ gas mixture $(\mathrm{pH} 7.4$, $37^{\circ} \mathrm{C}$ ). Any difference in response between direct and CPAE superfusion indicates the presence of factor(s) released from the CPAE cells in the perfusate. Compounds injected above the column of microcarrier beads without CPAE cells interact only with the bioassay ring, whereas compounds injected above the column of microcarrier beads with cells interact with both the CPAE cells and the bioassay ring.

The bioassay ring was stretched under direct superfusion in a stepwise manner until the response to $20 \mathrm{mM} \mathrm{KCl}$ was optimal (average 8 g). The removal of the endothelium was demonstrated by the absence of relaxation to $\mathrm{Bk}\left(10^{-8} \mathrm{M}\right)$ under direct superfusion, after precontraction with $\mathrm{PGF}_{2 \alpha}\left(10^{-5} \mathrm{M}\right)$. All experiments were done in the presence of indomethacin $\left(10^{-5} \mathrm{M}\right)$ to block PG synthesis (see reference 17 for review of the method).

Electrophysiology. $\mathrm{I}_{\mathrm{sc}}$ was measured in M-1 monolayers in an Ussing-type chamber as previously described (16). The entire chamber was placed in an incubator at $37^{\circ} \mathrm{C}$ and $5 \% \mathrm{CO}_{2}$ for the course of the experiment. The chamber contained four wells, filled with $0.9 \%$ saline, in which agar bridges and $\mathrm{Ag} / \mathrm{AgCl}$ electrodes were positioned. The electrodes connected to a voltage clamp (DVC-1000; W-P Instruments, Inc., New Haven, CT). The voltage clamp was zeroed daily with $0.9 \%$ saline before the experiment. $I_{x c}$ was measured for $2 \mathrm{~s}$ at 30 -s intervals. Transepithelial potential difference (PD) was measured during the 30-s intervals, thereby maintaining the culture in a predominant open-circuit condition. Once baseline recordings were stable, CPAE cells on microcarriers were added to the lumen and the bath. Once $\mathrm{I}_{\mathrm{sc}}$ was stable, Bk $\left(10^{-9} \mathrm{M}\right)$ or Ach $\left(10^{-7} \mathrm{M}\right)$ was added to both the lumen and bath. Recordings of $I_{s c}$ and PD from M-1 cells alone, recordings of $I_{s c}$ and PD from M-1 cells in the presence of CPAE cells, and recordings of $I_{s c}$ and PD from M-1 cells in the presence of CPAE cells and Bk were sequentially taken from the same M-1 cultures. (Similar studies were repeated in which Bk was replaced by Ach.) Each M-1 culture dish was an $n$ value of 1 .

In a second set of experiments, CPAE cells were pretreated with $10^{-4} \mathrm{M}$ N-Arg (Sigma Chemical Co., St. Louis, MO) for $15 \mathrm{~min}$ before their addition to the M- 1 cultures. On addition of the CPAE cells to the M-1 cultures, N-Arg was added to both the lumen and the bath to maintain the concentration at $10^{-4} \mathrm{M}$. As above, recordings of $\mathrm{I}_{\mathrm{sc}}$ and $P D$ from $M-1$ cells alone, recordings of $I_{s c}$ and $P D$ from $M-1$ cells in the presence of N-Arg-treated CPAE cells, and recordings of $\mathrm{I}_{\mathrm{sc}}$ and PD from M-1 cells in the presence of N-Arg-treated CPAE cells and Bk were sequentially taken from the same M-1 cultures. (Similar studies were repeated in which Bk was replaced with Ach.) Each M-1 culture dish was an $n$ value of 1 .

In another set of experiments, $10^{-5} \mathrm{M}$ methylene blue (Sigma Chemical Co.) was added to M-1 cultures. Once $\mathrm{I}_{\mathrm{sc}}$ was stable, CPAE cells on microcarriers were added to the lumen and bath, followed by addition of $\mathrm{Bk}\left(10^{-9} \mathrm{M}\right)$.

cGMP content. M-1 cells were grown to confluence on $31-\mathrm{mm}$ cross-linked collagen membranes. Isobutyl methyl xanthine $(1 \mathrm{mM})$ in HBSS solution containing $10 \mathrm{mM}$ Hepes was added to M-1 cells, CPAE cells, and cultures of M-1 and CPAE cells, alone or with $10^{-9} \mathrm{M}$ Bk. Samples were incubated for $20 \mathrm{~min}$ at $37^{\circ} \mathrm{C}$. The medium was aspirated and the cells were lysed with $300 \mu$ l of $5 \%$ TCA. The TCA was collected and frozen at $-70^{\circ} \mathrm{C}$ until the day of the assay. On the day of the assay, the acid was extracted from the samples with water-saturated ether. The samples were dried under $\mathrm{N}_{2}$ gas at room temperature, reconstituted in buffer, and assayed for CGMP using a kit from Biomedical Technologies Inc., Stoughton, MA. A total of four assays was run, and samples were run in duplicate. The inter- and intraassay coefficients of variation were 12.2 and $6.5 \%$, respectively. The detectable range was 4-400 fmol. To examine the recovery of cGMP during the extraction process, $150 \mathrm{fmol}$ of CGMP in $300 \mu \mathrm{l}$ of TCA was added to permeable collagen membranes (without cells); $94 \pm 2.5 \%$ of it was recovered. Recoveries were monitored in each experiment.

Statistics. Values are reported as the mean \pm SE. Individual culture dishes were considered as an $n$ value of 1 . Data from transport studies were evaluated with analysis of variance for repeat measures and multiple paired $t$ tests with a Bonferroni adjustment to determine significant differences between each of the treatments. Data from cGMP measurements were evaluated using analysis of variance with three factors and multiple unpaired $t$ tests with Bonferroni adjustment to determine significant differences between treatment groups. A $\geq 95 \%$ probability that the means were different was considered significant.

\section{Results}

Bioassay of EDRF production by CPAE cells. To demonstrate that our cultured CPAE cells release EDRF, we examined their ability to relax precontracted vascular rings (Fig. 1). Endothelial-denuded vascular rings from canine coronary arteries were superfused either directly or with a solution exposed to CPAE cells. $10^{-8} \mathrm{M}$ Bk infused in the direct superfusion caused a small but insignificant contraction of the preconstricted rings. $\mathrm{Bk}$ infused in the endothelial superfusion produced a $100 \%$ relaxation of the preconstricted rings. These data demonstrate that our cultured CPAE cells produce and release a vasodilator substance (EDRF) in response to Bk.

Electrophysiology. To examine the effects of $\mathrm{Bk}$ alone on transport in M-1 cells, Bk was added to the bath and lumen of $\mathrm{M}-1$ cultures in doses of $10^{-5}, 10^{-6}, 10^{-7}, 10^{-8}$, and $10^{-9} \mathrm{M}$ (Fig. 2). Bk did not affect $I_{s c}$ or PD at doses $<10^{-6} \mathrm{M}$. To ensure against a direct effect of $\mathrm{Bk}$, a dose 1,000-fold less than that necessary to elicit a response was used.

The effects of Bk on $I_{s c}$ and PD were measured in cultures of M-1 cells in the presence of CPAE cells. The addition of CPAE cells to M-1 cultures did not affect $I_{s c}$ (Fig. 3). Baseline $I_{s c}$ in M-1 monolayers was $47 \pm 4 \mu \mathrm{A} / \mathrm{cm}^{2}$ before CPAE cell addition and $43 \pm 4.5 \mu \mathrm{A} / \mathrm{cm}^{2}$ after addition. PD decreased slightly but significantly, from $-20 \pm 1$ to $-16 \pm 2 \mathrm{mV}(P<0.01)$. The subsequent addition of $B k$ inhibited $I_{s c}$ from $43 \pm 4.5$ to $26 \pm 4 \mu \mathrm{A} /$ $\mathrm{cm}^{2}$, a $40 \pm 6 \%$ decrease $(P<0.001)$ (Fig. 3). PD decreased from $-16 \pm 2$ to $-9 \pm 1 \mathrm{mV}$ with Bk $(P<0.001)$. The addition of vehicle to cultures of M-1 and CPAE cells produced no significant effect on transport. These experiments were repeated us- 


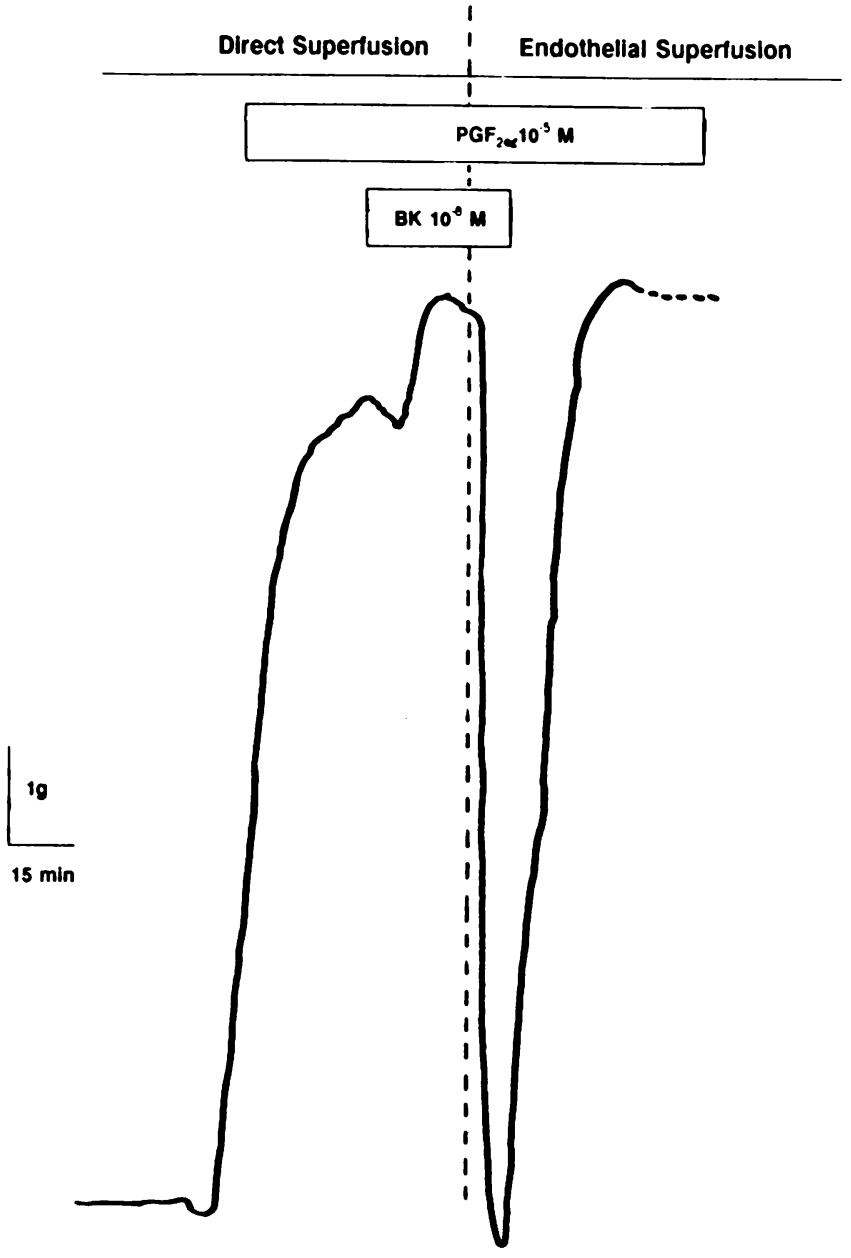

Figure 1. A representative isometric tension recording of the bioassay ring of canine coronary artery (without endothelium). Under direct superfusion the ring was contracted with $\mathrm{PGF}_{2 \alpha}$ and $\mathrm{Bk}$ produced a small contraction, confirming the absence of endothelium. When switching to CPAE superfusion, Bk produced a complete relaxation, confirming that the CPAE cells produce a vasodilator substance (EDRF).

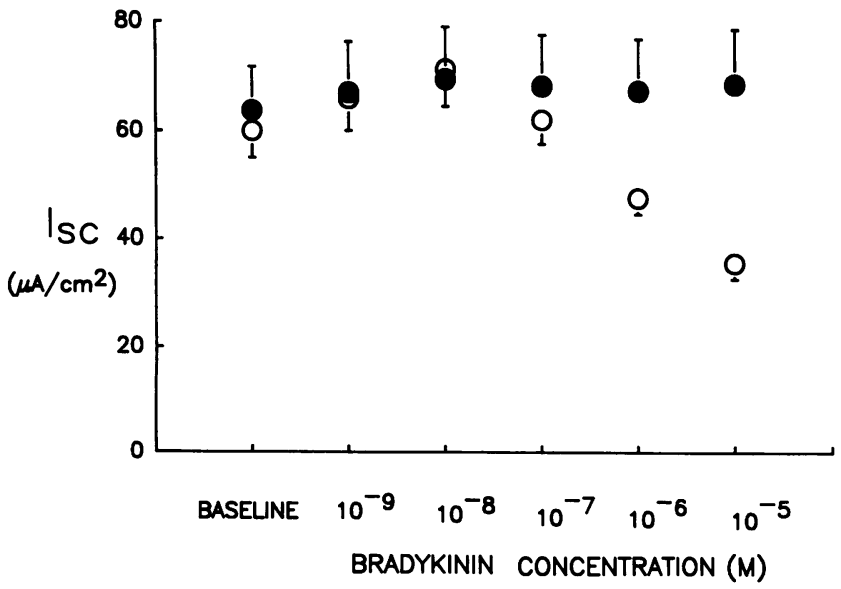

Figure 2. The effect of various concentrations of $\mathbf{B k}$ on $\mathrm{I}_{\mathrm{sc}}$. A significant interaction effect $(P=0.001)$ was found between group and dosage $(n=6)$. $\bullet$, vehicle; $\circ$, bradykinin.

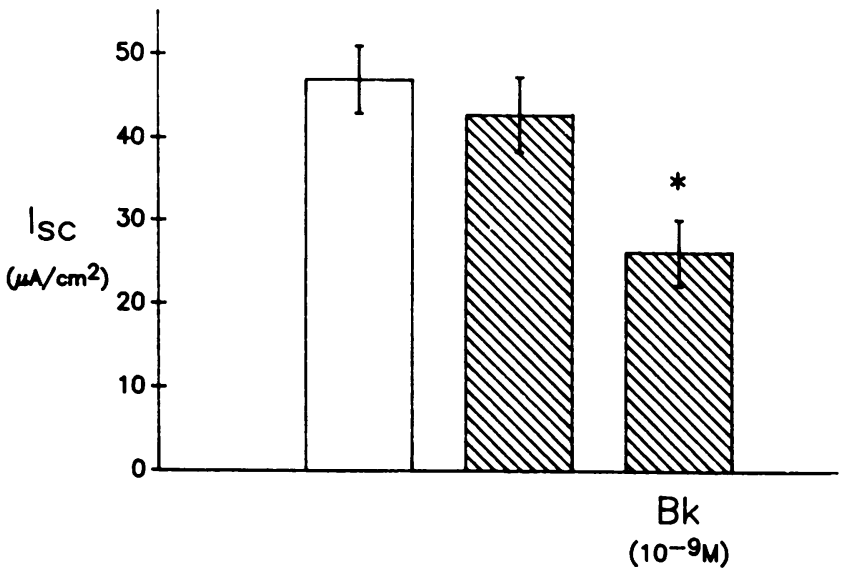

Figure 3. The effect of $10^{-9} \mathrm{M}$ Bk on $\mathrm{I}_{\mathrm{sc}}$ in the presence of CPAE cells. Control $\mathrm{I}_{\mathbf{s c}}$ values were measured in $\mathrm{M}-1$ monolayers alone. Cocultures consisted of M-1 monolayers and CPAE cells on microcarriers. Addition of CPAE cells produced no significant effect on $\mathrm{I}_{\mathrm{sc}}$ in M-1 cells. Bk was added to the bath and lumen. Bk-stimulated release of EDRF decreased $I_{s c} 40 \pm 6 \%$ in the cocultures. Vehicle addition had no significant effect on coculture $\mathrm{I}_{\mathrm{sc}}\left(n=6 ;{ }^{*} P<0.001\right)$. $\square$, M-1 cells; \$, coculture.

ing $10^{-7} \mathrm{M}$ Ach as the stimulatory agent rather than Bk. Addition of Ach to $\mathrm{M}-1$ cells produced no significant effect on $\mathrm{I}_{\mathrm{sc}}$ or PD. However, addition of Ach to M-1 cells in the presence of CPAE cells inhibited $I_{s c}$ from $64 \pm 9$ to $33 \pm 4 \mu \mathrm{A} / \mathrm{cm}^{2}$, a $44 \%$ decrease, and PD from $-42 \pm 3$ to $-28 \pm 3 \mathrm{mV}$, a $33 \%$ decrease.

Addition of N-Arg $\left(10^{-4} \mathrm{M}\right)$ alone to M-1 cultures had no significant effect on $\mathrm{I}_{\mathrm{sc}}$ or PD. Addition of $\mathrm{N}$-Arg-treated CPAE cells to $M-1$ cultures also produced no significant effect on $I_{\text {sc }}$ (Fig. 4): $46 \pm 4 \mu \mathrm{A} / \mathrm{cm}^{2}$ before CPAE cell addition and $42 \pm 5 \mu \mathrm{A} / \mathrm{cm}^{2}$ afterwards. PD $(-25.5 \pm 6$ to $-27 \pm 7.5 \mathrm{mV})$ did not significantly change. Fig. 4 also shows the effect of $\mathrm{Bk}$ on N-Arg-treated cultures of M-1 and CPAE cells. There was no

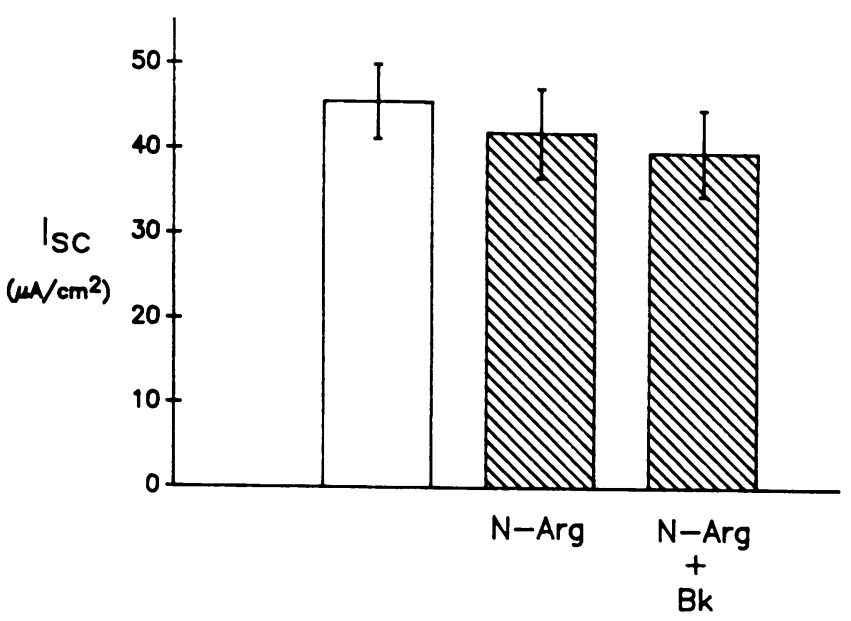

Figure 4. The effect of $10^{-9} \mathrm{M}$ Bk on $\mathrm{I}_{\mathrm{sc}}$ in the presence of N-Argtreated CPAE cells. Control $I_{s c}$ values were measured in M-1 monolayers alone. Cocultures consisted of $\mathrm{M}-1$ monolayers and $10^{-4} \mathrm{M} \mathrm{N}$ Arg-treated CPAE cells on microcarrier beads. Addition of N-Argtreated CPAE cells produced no significant effect on $\mathrm{I}_{\mathrm{sc}}$ in $\mathrm{M}-1$ monolayers. Bk was added to the bath and lumen in the presence of $\mathrm{N}$-Arg-treated CPAE cells and produced no significant effect on $\mathrm{I}_{\mathbf{s c}}$

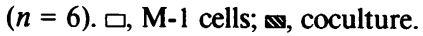




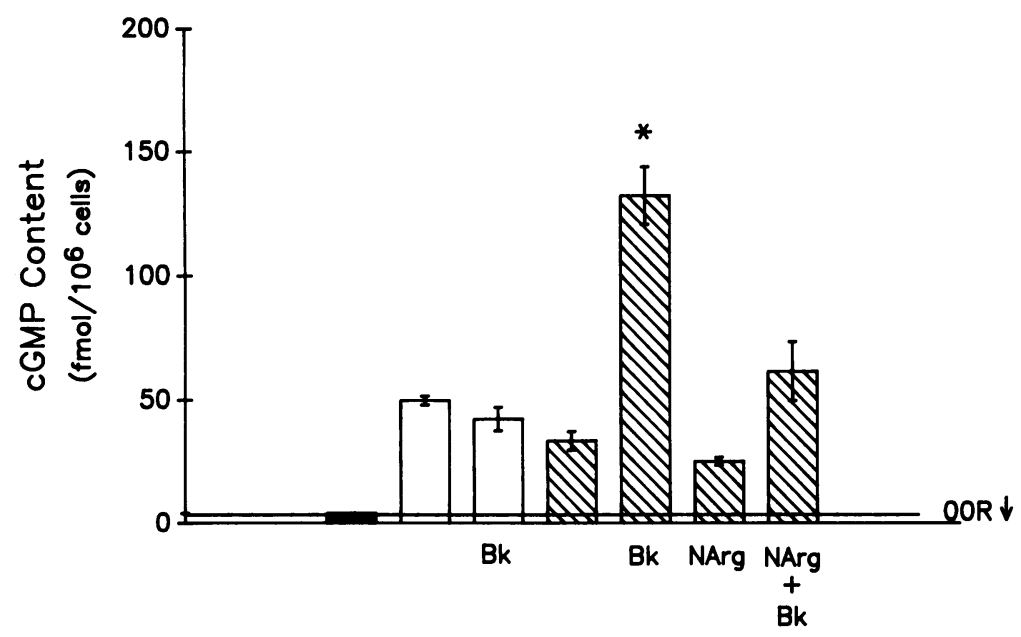

Figure 5. The effect of $10^{-9} \mathrm{M}$ Bk on cGMP content in cocultures of M- 1 and CPAE cells. OOR $\downarrow$ denotes values below the 4-fmol limit of detectability. Bk was added to the bath and lumen and subsequently produced an $\sim 300 \%$ increase in cGMP content in cocultures of $\mathrm{M}-1$ and CPAE cells. cGMP content in N-Arg-treated cocultures challenged with $\mathrm{Bk}$ was $61.4 \pm 12 \mathrm{fmol} / 10^{6} \mathrm{M}-1$ cells, not significantly higher than coculture baseline content $\left(n=5-11 ;{ }^{*} P<0.001\right) . \square$, media; $\square$, M-1 cells; $\$$, coculture. significant change in $I_{s c}\left(42 \pm 5\right.$ to $\left.40 \pm 5 \mu \mathrm{A} / \mathrm{cm}^{2}\right)$ or $P D$ $(-27 \pm 7.5$ to $-22 \pm 6 \mathrm{mV})$. Similarly, when Ach was given to $\mathrm{N}$-Arg-treated cultures of M-1 and CPAE cells, $I_{\text {sc }}(48 \pm 3$ to $\left.46 \pm 5 \mu \mathrm{A} / \mathrm{cm}^{2}\right)$ and $\mathrm{PD}(-34 \pm 6$ to $-32 \pm 6 \mathrm{mV})$ did not change.

Addition of methylene blue $\left(10^{-5} \mathrm{M}\right)$ alone to $\mathrm{M}-1$ cultures had no significant effect on $\mathrm{I}_{\mathrm{sc}}\left(51 \pm 2\right.$ to $\left.54 \pm 1 \mu \mathrm{A} / \mathrm{cm}^{2}\right)$ or PD $(-37 \pm 2$ to $-39 \pm 2 \mathrm{mV})$. Addition of $\mathrm{Bk}\left(10^{-9} \mathrm{M}\right)$ to methylene blue-treated M-1 cells in the presence of CPAE cells also produced no significant effect on $I_{s c}(54 \pm 0.5$ to $56 \pm 0.5 \mu \mathrm{A} /$ $\left.\mathrm{cm}^{2}\right)$ or PD $(-40 \pm 1$ to $-39 \pm 1 \mathrm{mV})$.

cGMP content. The cGMP contents of CPAE cells alone and those stimulated with Bk were below the limits of detectability $(<4 \mathrm{fmol})$. The cGMP content of the media was also below detectable limits (Fig. 5). The cGMP content of individual cultures of M-1 cells alone and those stimulated with $\mathrm{Bk}$ in the absence of CPAE cells was $49.7 \pm 1.8$ and $42.2 \pm 4.7 \mathrm{fmol} / 10^{6}$ cells, respectively. Cultures of M-1 and CPAE cells contained 33.3 $\pm 3.7 \mathrm{fmol}$ of cGMP per million M-1 cells, which increased to $132.0 \pm 11.7 \mathrm{fmol} / 10^{6} \mathrm{M}-1$ cells with the addition of $\mathrm{Bk}\left(10^{-9}\right.$ M). The content of CGMP was stimulated $\sim 300 \%$ by Bk addition to cultures of M-1 and CPAE cells compared with unstimulated cultures. When cultures of M-1 and CPAE cells were treated with $\mathrm{N}$-Arg and challenged with $\mathrm{Bk}$, the cGMP content was $61.4 \pm 12 \mathrm{fmol} / 10^{6} \mathrm{M}-1$ cells, not significantly higher than baseline culture levels.

\section{Discussion}

Our study demonstrated that Bk or Ach addition to M-1 cells, in the presence of CPAE cells, decreased transport and increased cGMP content. Inhibition of transport was blocked by $\mathrm{N}$-Arg, a competitive inhibitor of EDRF synthesis (6), and methylene blue, an inhibitor of soluble guanylate cyclase (9). Stimulation of cGMP content in M-1 cells was also partially blocked by N-Arg.

EDRF is a mediator of vascular tone and therefore participates in the regulation of peripheral resistance and, consequently, blood pressure. EDRF may also regulate blood pressure via effects on fluid and solute excretion in the kidney. It has been shown that stimulation of EDRF release in the kidney induces a natriuresis and diuresis without affecting glomerular filtration rate $(10,11)$. This would suggest that EDRF either has direct renal tubular effects on sodium reabsorption or causes hemodynamic effects that alter sodium reabsorption.
We know of no studies that directly address these possibilities and believe the present study provides the first evidence that EDRF has an effect on transport in cultured CCD cells.

The labile nature of EDRF raises the question of whether it remains intact long enough to diffuse from the endothelium to the CCD in vivo to affect transport. However, it can easily be demonstrated that EDRF can reach the collecting duct before it is degraded. Assuming that the distance EDRF must diffuse to reach the CCD can be represented by the average distance from the afferent arteriole to the CCD, $0.1 \mathrm{~mm} \mathrm{(18),}{ }^{2}$ and that the diffusivity of EDRF can be approximated by that of a structurally very similar molecule, $\mathrm{CO},{ }^{3} 2 \times 10^{-5} \mathrm{~cm}^{2} / \mathrm{s}$, then the time necessary for $50 \%$ of the EDRF produced by the afferent arteriole to diffuse $0.1 \mathrm{~mm}$ would be $5 \mathrm{~s}$. This value is much less than the 30-s half-life of EDRF.

The inhibition of transport observed in this study is likely to be due to EDRF rather than to the agonists used to release EDRF for a number of reasons. First, we used two different agents, Bk and Ach, and the results were similar. Second, the doses of these agents used to release EDRF on their own had no effect on $I_{s c}$. Finally, the inhibition could be prevented by a competitive inhibitor of EDRF synthesis, as well as by an inhibitor of soluble guanylate cyclase.

It has been shown previously that atrial natriuretic peptide, which acts via cGMP, inhibits transport in the collecting duct (21) and that EDRF acts via cGMP in vascular smooth muscle $(7,8)$; therefore, it seemed likely that cGMP was the second messenger that induced inhibition of transport in the present experiments. This is supported by the observation that measured cGMP content increased $300 \%$ when EDRF release was stimulated in cultures of M-1 and CPAE cells and was blocked by the addition of N-Arg.

2. This distance assumes that there is only a single source of EDRF from the afferent arteriole. Clearly there would be several afferent arterioles surrounding a collecting duct. Additionally, it is likely that there are other sources of EDRF besides the afferent arteriole (19), such as the renal capillaries and larger renal vessels (20).

3. The diffusivity of EDRF is likely to be very similar to $\mathrm{CO}$, since this parameter is primarily determined by the square root of the molecular weight of a compound and to some extent the structure. The molecular weight of $\mathrm{CO}$ differs from NO by only $6 \%$ and the structures are analogous. 
Endothelial cells may produce other substances besides EDRF that could inhibit $I_{s c}$, such as endothelin (22); however, since N-Arg and methylene blue blocked the inhibition of transport caused by Bk or Ach in the presence of CPAE cells, this would suggest that the inhibition was specifically due to the release of EDRF. Furthermore, CGMP has been proposed to be the second messenger of EDRF in smooth muscle $(7,8)$; therefore, the observation that cGMP was stimulated by the addition of Bk in cultures of M-1 and CPAE cells further supports the contention that EDRF is involved.

The M-1 cell line possesses many antigenic and differentiated transport properties of the CCD epithelium (16); therefore, the EDRF-stimulated inhibition of transport observed in the M-1 cells is probably also expressed in vivo. It is true, however, that phenomena that occur in cultured cells provide only indirect evidence that the indicated response is indeed physiological; thus, further studies are required in order to determine whether EDRF has direct tubular effects in vivo.

In conclusion, EDRF release from CPAE cells decreased transport in M-1 CCD cells and increased cGMP levels. This decrease in transport may account for the renal effects evoked by EDRF in in vivo studies.

\section{Acknowledgments}

This work was supported by a grant from the National Institutes of Health (HL-28982).

\section{References}

1. Palmer, R. M. J., A. G. Ferrige, and S. Moncada. 1987. Nitric oxide release accounts for the biological activity of endothelium-derived relaxing factor. $\mathrm{Na}$ ture (Lond.). 327:524-525.

2. Wei, E. P., and H. A. Kontos. $1990 . \mathrm{H}_{2} \mathrm{O}_{2}$ and endothelium-dependent cerebral arteriolar dilation: implications for the identity of endothelium-derived relaxing factor generated by acetylcholine. Hypertension. 16:162-169.

3. Myers, P. R., R. L. Minor, Jr., R. Guerra, Jr., J. N. Bates, and D. G. Harrison. 1990. Vasorelaxant properties of the endothelium-derived relaxing factor more closely resemble S-nitrosocysteine than nitric oxide. Nature (Lond.). 345:161-163.

4. Palmer, R. M. J., D. S. Ashton, and S. Moncada. 1988. Vascular endothelial cells synthesize nitric oxide from L-arginine. Nature (Lond.). 333:664-666.
5. Furchgott, R. F., and P. M. Vanhoutte. 1989. Endothelium-derived relaxing and contracting factors. FASEB (Fed. Am. Soc. Exp. Biol.) J. 3:2007-2018.

6. Moore, P. K., O. A. al-Sayeh, N. W. S. Chong, R. A. Evans, and A. Gibson. 1990. $L-N^{G}$-nitro arginine (L-NOARG), a novel, L-arginine-reversible inhibitor of endothelium-dependent vasodilation in vitro. Br. J. Pharmacol. 99:408-412.

7. Vanhoutte, P. M. 1989. Endothelium and control of vascular function. Hypertension. 13:658-667.

8. Shultz, P. J., A. E. Schorer, and L. Raij. 1990. Effects of endothelium-derived relaxing factor and nitric oxide on rat mesangial cells. Am. J. Physiol. 258:F162-F167.

9. Martin, W., G. M. Villani, D. Jothianandan, and R. F. Furchgott. 1985. Selective blockade of endothelium-dependent and glyceryl trinitrate-induced relaxation by hemoglobin and by methylene blue in the rabbit aorta. J. Pharmacol. Exp. Ther. 232:708-716.

10. Lahera, V., M. G. Salom, M. J. Fiksen-Olsen, L. Raij, and J. C. Romero. 1990. Effects of $\mathrm{N}^{\mathrm{G}}$-monomethyl-L-arginine and $\mathrm{L}$-arginine on acetylcholine renal response. Hypertension. 15:659-663.

11. Lahera, V., M. G. Salom, M. J. Fiksen-Olsen, and J. C. Romero. 1991. Mediatory role of endothelium-derived nitric oxide in renal vasodilatory and excretory effects of bradykinin. Am. J. Hypertension. 4:260-262.

12. Zeidel, M. L., P. Silva, B. M. Brenner, and J. L. Seifter. 1987. cGMP mediates effects of atrial peptides on medullary collecting duct cells. Am. J. Physiol. 252:F551-F559.

13. Nonoguchi, H., J. M. Sands, and M. A. Knepper. 1989. ANF inhibits $\mathrm{NaCl}$ and fluid absorption in cortical collecting duct of rat kidney. Am. J. Physiol. 256:F179-F186.

14. Zeidel, M. L., K. Deepak, P. Silva, M. Burrowes, and B. M. Brenner. 1988. Atrial natriuretic peptides inhibit conductive sodium uptake by rabbit inner medullary collecting duct cells. J. Clin. Invest. 82:1067-1074.

15. Nonoguchi, H., J. M. Sands, and M. A. Knepper. 1988. Atrial natriuretic factor inhibits vasopressin-stimulated osmotic water permeability in rat inner medullary collecting duct. J. Clin. Invest. 82:1383-1390.

16. Stoos, B. A., A. Náray-Fejes-Tóth, O. A. Carretero, S. Ito, and G. FejesTóth. 1991. Characterization of a mouse cortical collecting duct cell line. Kidney Int. 39:1168-1175.

17. Boulanger, C., H. Hendrickson, R. R. Lorenz, and P. M. Vanhoutte. 1989. Release of different relaxing factors by cultured porcine endothelial cells. Circ. Res. 64:1070-1078.

18. Kaissling, B., and W. Kriz. 1979. Structural Analysis of the Rabbit Kidney. Springer-Verlag, New York. 121 pp.

19. Ito, S., C. S. Johnson, and O. A. Carretero. 1991. Modulation of angiotensin II-induced vasoconstriction by endothelium-derived relaxing factor in the isolated microperfused rabbit afferent arteriole. J. Clin. Invest. 87:1656-1663.

20. Kon, V., R. C. Harris, and I. Ichikawa. 1990. A regulatory role for large vessels in organ circulation. Endothelial cells of the main renal artery modulate intrarenal hemodynamics in the rat. J. Clin. Invest. 85:1728-1733.

21. Antonino, R. S., and L. H. Kudo. 1990. Atrial peptide and cGMP effects on $\mathrm{NaCl}$ transport in inner medullary collecting duct. Am. J. Physiol. 259:F258F268.

22. Yanagisawa, M., H. Kurihara, S. Kimura, Y. Tomobe, M. Kobayashi, Y. Mitsui, Y. Yazaki, K. Goto, and T. Masaki. 1988. A novel potent vasoconstrictor peptide produced by vascular endothelial cells. Nature (Lond.). 332:411-415. 